\title{
HISTOLOGIA E HISTOQUÍMICA DO DESENVOLVIMENTO OVOCITÁRIO DE Callichirus major (CRUSTACEA: AXIIDEA)
}

\author{
Tugstênio Lima de Souza ${ }^{1}$ \\ Adriane Araújo Braga \\ Erika Takagi Nunes ${ }^{3}$
}

Resumo: Callichirus major, conhecido popularmente como "corrupto", é uma espécie animal de grande importância na indústria da pesca, por ser utilizado como isca viva. O presente estudo visou caracterizar o desenvolvimento ovocitário desta espécie de crustáceo por meio de microscopia de luz. Os animais foram coletados ao longo da Praia do Corujão, em Piúma/ES e, em laboratório, suas gônadas femininas foram dissecadas e submetidas ao processamento histológico de rotina e a testes histoquímicos. Nos ovários são encontrados os componentes germinativos (oogônias e ovócitos I, II, III e IV). A histoquímica demonstrou que os ovócitos, quanto mais desenvolvidos, mais reativos são para proteínas e polissacarídeos. Alguns ovócitos tipo II apresentaram grânulos cromófobos em seu citoplasma, sugerindo o armazenamento precoce de conteúdo lipídico. Além disso, os ovócitos III apresentam a região citoplasmática periférica altamente reativa para os testes histoquímicos, havendo, nesta fase, o inicio do armazenamento de compostos de origem exógena.

Palavras-chave: Histoquímica; Corrupto; Ovogênese; Reprodução, Decapoda.

\footnotetext{
1 Ciências Biológicas/Universidade Federal do Espírito Santo, Brasil. E-mail: tugstenio94@hotmail.com.

2 Ciências Biológicas/Universidade Federal do Espírito Santo, Brasil. E-mail: dricrab@yahoo.com.br.

${ }^{3}$ Ciências Biológicas/Universidade Federal do Espírito Santo, Brasil. E-mail: erikatnunes@yahoo.com.br.
} 